NISTIR 7216

\title{
A Simulation Study of a Hierarchical, Rule-Based Method for System-Level Fault Detection and Diagnostics in HVAC Systems
}

Jeffrey Schein

Steven Bushby

U.S DEPARTMENT OF COMMERCE National Institute of Standard and Technology Building Environment Division Building and Fire Research Laboratory Gaithersburg, MD 20899-8631 

NISTIR 7216

\section{A Simulation Study of a Hierarchical, Rule- Based Method for System-Level Fault Detection and Diagnostics in HVAC Systems}

Jeffrey Schein Steven Bushby

U.S DEPARTMENT OF COMMERCE National Institute of Standard and Technology Building Environment Division Building and Fire Research Laboratory Gaithersburg, MD 20899-8631

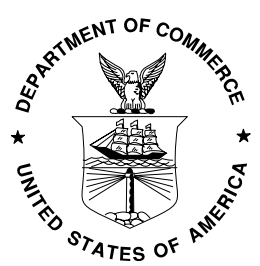

U.S. Department of Commerce Carlos M. Gutierrez, Secretary 



\section{A Simulation Study of a Hierarchical, Rule-based Method for System-level Fault Detection and Diagnostics in HVAC Systems}

\section{Abstract}

A system-level fault detection and diagnostic (FDD) method for heating, ventilation, and air conditioning (HVAC) systems was developed. It functions as an interface between multiple, equipment-specific FDD tools and a human operator. The method resolves conflicting fault reports from equipment-specific FDD tools, performs FDD at the system level, and presents an integrated view of an HVAC system's fault status to an operator. A simulation study to test and evaluate the method was conducted.

\section{Introduction}

Building HVAC equipment routinely fails to satisfy performance expectations envisioned at design. Such failures often go unnoticed for extended periods of time. Additionally, higher expectations are being placed on a combination of different and often conflicting performance measures, such as energy efficiency, indoor air quality, comfort, reliability, limiting peak demand on utilities, etc. To meet these expectations, the processes, systems, and equipment used in both commercial and residential buildings are becoming increasingly sophisticated which inadvertently causes more problems. This development both necessitates the use of automated diagnostics to ensure fault-free operation and enables diagnostic capabilities for the various building systems by providing a distributed platform that is powerful and flexible enough to perform fault detection and diagnostics (FDD).

A number of FDD tools that are emerging from research are described in [1] and [2]. Most of these tools are equipment-specific, meaning they are meant to detect faults in a chiller, air handling unit (AHU), etc. Results from a study to field-test equipment-specific FDD tools for AHUs and terminal units [3] show the need for another tool to act as an interface between equipment-specific FDD tools and the building operator in order to resolve conflicting fault reports from the various equipment-specific FDD tools and to present an integrated view of the HVAC system's fault status to the operator. In one case, a fault detected in a terminal unit at one of the field sites, in which the zone air temperature increased well above the setpoint, was traced to a problem with the supply air temperature provided by the AHU serving the terminal unit. The results from another site include several cases of terminal unit faults caused by problems with the supply air temperature and pressure provided by the associated AHU. There are also numerous terminal unit and AHU faults documented, which were traced to scheduling inconsistencies between terminal units, AHUs, and the chilled water plant.

The common thread in the previous examples is the set of hierarchical relationships between the different pieces of equipment comprising the HVAC system. Each AHU delivers supply air to the terminal units it serves, the chilled water plant supplies chilled water to the AHUs, and the boiler plant provides hot water to the AHUs and terminal units. These relationships are each characterized by a single "source" supplying multiple "loads". In each case, there is an air or water fluid interface between the "source" and the "loads". The temperature and pressure of the fluid are maintained at setpoint values by the "source" equipment in order to enable the "load" equipment to operate as intended. Normally, each AHU and the terminal units it serves form a separate, distinct hierarchy. However, the output of each of the chillers is aggregated to form a single chilled water plant, which then supplies chilled water to all the loads in the system. Similarly, the output of the boilers is aggregated to form a single boiler plant supplying all the hot water loads in the system. 
In order to present an integrated view of an HVAC system's fault status to the operator, the system-level FDD method developed in this project uses these hierarchical relationships to act as a filter, resolving conflicting fault reports from equipment-specific FDD tools. Knowledge of these relationships, combined with access to some selected raw data, also allows the method to perform FDD at the system level.

\section{Methodology}

A number of different approaches to solve the problem of FDD integration and conflict resolution were considered. One possible approach is described in [4], in which a high level structural model is used as a topological basis to link together models of each of the components of the mechanical system. Any of a number of different types of models could be used for the individual components of the system. However, the computational demands of a model-based solution require that it run on a general-purpose computer. In general, it is not possible for any of the various embedded devices that make up the balance of the building automation system to perform model-based FDD analysis.

Another alternative under consideration was a case-based solution to conflict resolution as described in [5]. Briefly, a template is defined containing sufficient fields to describe the state of the HVAC system. Current data are entered into the template, and a database of historical cases is searched for the closest match to the current state. Several different algorithms can be used to determine which historical case is the best match. This approach, while less computationally demanding than the model-based approach, requires far more memory than is available from an embedded device in a typical building automation system and therefore, as with the model-based solution, requires a general-purpose computer.

A rule-based approach has a number of advantages, including the transparency, flexibility, and adaptability obtained by expressing the knowledge base as a set of rules, explicitly separated from the decision-making framework [6]. Furthermore, this approach is suitable to run on an embedded device with respect to both computational and memory requirements. The rule-based approach was selected because it offers the most flexibility for implementation in a variety of control system architectures.

The proposed system-level FDD tool consists of two components: a hierarchical decision-making framework and a set of rules. The decision-making framework collects fault reports and raw data from the local equipment controllers and passes these data to the rule set for evaluation. The rules are used to determine whether to pass the fault reports on to a human operator. Figure 1 is a schematic illustration of the framework. 


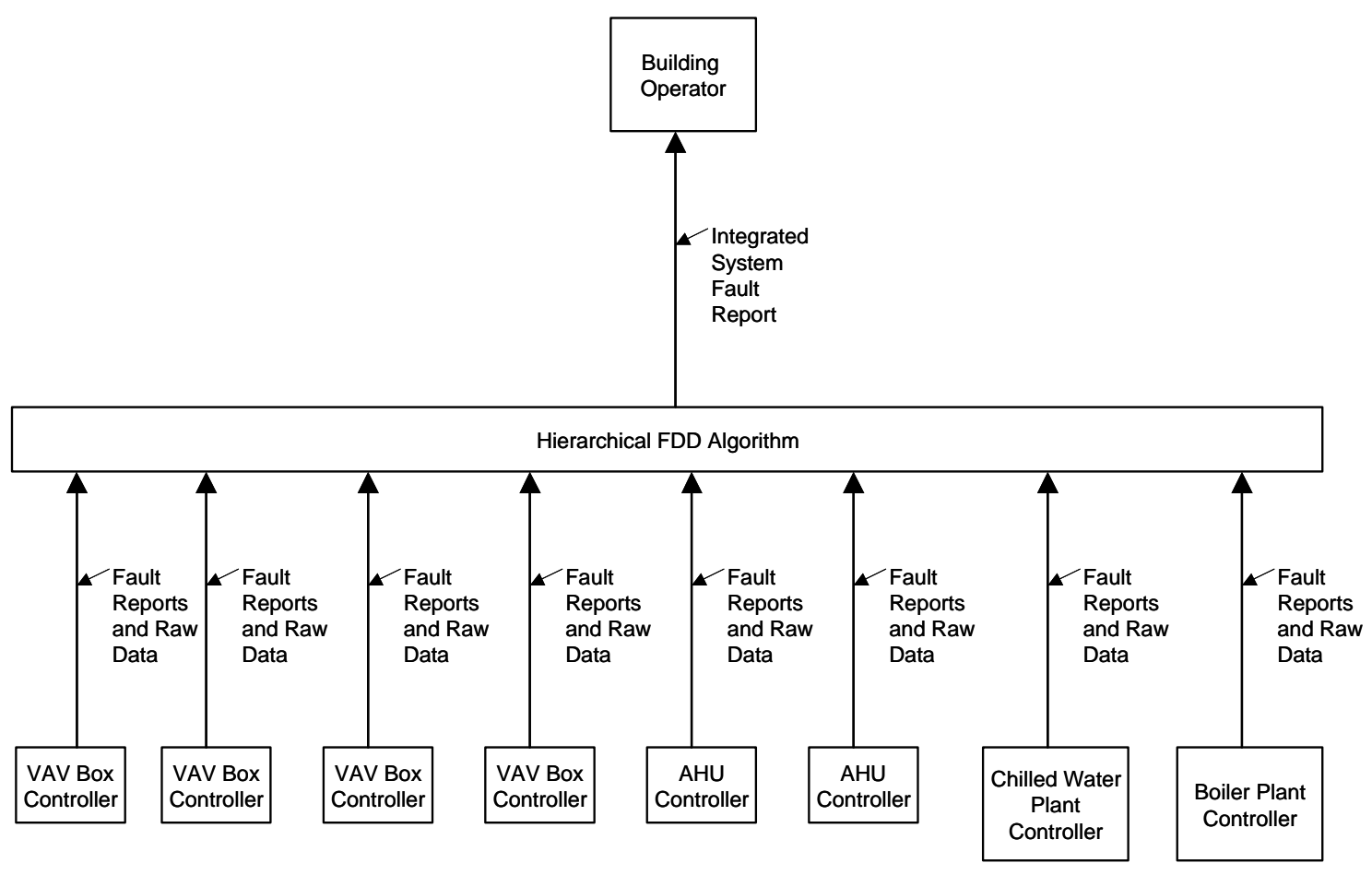

Figure 1. The Hierarchical-Decision Making Framework

The fundamental methodology consists of four general principles for integrating equipment-specific fault reports and resolving conflicts given the source-load hierarchical relationships between the different pieces of equipment and subsystems in an HVAC system:

1. Fault reports from a load are suppressed if there are any fault reports from a source serving that load.

2. A scheduling conflict between a source and any of the loads it serves is considered a fault associated with the source. Any fault reports from any of the loads served by the faulty source are suppressed.

3. A fault in the air or water fluid interface between a source and the loads it serves is considered a fault associated with the source. Any fault reports from any of the loads served by the faulty source are suppressed.

4. Multiple fault reports from the loads served by a source are considered a fault associated with the source. Any fault reports from any of the loads served by the faulty source are suppressed.

The rule set was generated by applying these general principles to the hierarchical subsystems in an HVAC system. See Table 1. A software implementation combining the hierarchical decision-making framework and the rule set was developed using the algorithm illustrated in Figure 2. 
Table 1. Rule set for integrating multiple fault reports.

\begin{tabular}{|c|c|c|}
\hline Principle & Subsystem & Rule \\
\hline \multirow{4}{*}{$\begin{array}{l}\text { Fault reports from a load are } \\
\text { suppressed if there are any fault } \\
\text { reports from a source serving } \\
\text { that load. }\end{array}$} & Chiller plant & $\begin{array}{l}\text { 1. If there are any equipment-level chiller plant faults, pass them on to the } \\
\text { operator, and suppress any AHU or terminal unit faults. }\end{array}$ \\
\hline & Boiler plant & $\begin{array}{l}\text { 2. If there are any equipment-level boiler plant faults, pass them on to the } \\
\text { operator, and suppress any AHU or terminal unit faults. }\end{array}$ \\
\hline & AHU & $\begin{array}{l}\text { 3. If there are no chiller plant or boiler plant faults and there are any } \\
\text { equipment-level AHU faults, pass them on to the operator, and suppress any } \\
\text { fault reports from the terminal units served by the faulty AHU. }\end{array}$ \\
\hline & $\begin{array}{l}\text { Terminal } \\
\text { unit }\end{array}$ & $\begin{array}{l}\text { 4. If there are no chiller plant or boiler plant faults and there are no faults in the } \\
\text { associated AHU, pass any equipment-level terminal unit faults on to the } \\
\text { operator. }\end{array}$ \\
\hline \multirow{3}{*}{$\begin{array}{l}\text { A scheduling conflict between } \\
\text { a source and any of the loads it } \\
\text { serves is considered a fault } \\
\text { associated with the source. } \\
\text { Any fault reports from any of } \\
\text { the loads served by the faulty } \\
\text { source are suppressed. }\end{array}$} & Chiller plant & $\begin{array}{l}\text { 5. If the chiller plant is off and any AHU is on and requires chilled water, } \\
\text { report a chiller plant scheduling fault to the operator, and suppress any AHU } \\
\text { or terminal unit faults. }\end{array}$ \\
\hline & Boiler plant & $\begin{array}{l}\text { 6. If the boiler plant is off and any AHU or terminal unit is on and requires hot } \\
\text { water, report a boiler plant scheduling fault to the operator, and suppress any } \\
\text { AHU or terminal unit faults. }\end{array}$ \\
\hline & AHU & $\begin{array}{l}\text { 7. If there are no chiller plant or boiler plant faults and any AHU is off while } \\
\text { any of the terminal units it serves is in occupied mode, report an AHU } \\
\text { scheduling fault to the operator, and suppress any fault reports from the } \\
\text { terminal units served by the faulty AHU. }\end{array}$ \\
\hline \multirow{6}{*}{$\begin{array}{l}\text { A fault in the interface between } \\
\text { a source and the loads it serves } \\
\text { is considered a fault associated } \\
\text { with the source. Any fault } \\
\text { reports from any of the loads } \\
\text { served by the faulty source are } \\
\text { suppressed. }\end{array}$} & Chiller plant & $\begin{array}{l}\text { 8. If the chilled water supply temperature is greater than its setpoint (subject to } \\
\text { the given threshold), report a chiller plant supply temperature fault to the } \\
\text { operator, and suppress any AHU or terminal unit faults. }\end{array}$ \\
\hline & Chiller plant & $\begin{array}{l}\text { 9. If the chilled water supply pressure is less than its setpoint (subject to the } \\
\text { given threshold), report a chiller plant supply pressure fault to the operator, } \\
\text { and suppress any AHU or terminal unit faults. }\end{array}$ \\
\hline & Boiler plant & $\begin{array}{l}\text { 10. If the hot water supply temperature is less than its setpoint (subject to the } \\
\text { given threshold), report a boiler plant supply temperature fault to the } \\
\text { operator, and suppress any AHU or terminal unit faults. }\end{array}$ \\
\hline & Boiler plant & $\begin{array}{l}\text { 11. If the hot water supply pressure is less than its setpoint (subject to the given } \\
\text { threshold), report a boiler plant supply pressure fault to the operator, and } \\
\text { suppress any AHU or terminal unit faults. }\end{array}$ \\
\hline & AHU & $\begin{array}{l}\text { 12. If there are no chiller plant or boiler plant faults and the AHU supply air } \\
\text { temperature is greater than its setpoint (subject to the given threshold), } \\
\text { report an AHU supply air temperature fault to the operator, and suppress any } \\
\text { fault reports from the terminal units served by the faulty AHU. }\end{array}$ \\
\hline & AHU & $\begin{array}{l}\text { 13. If there are no chiller plant or boiler plant faults and the AHU supply air } \\
\text { pressure is less than its setpoint (subject to the given threshold), report an } \\
\text { AHU supply air pressure fault to the operator, and suppress any fault reports } \\
\text { from the terminal units served by the faulty AHU. }\end{array}$ \\
\hline \multirow{4}{*}{$\begin{array}{l}\text { Multiple fault reports from the } \\
\text { loads served by a source are } \\
\text { considered a fault associated } \\
\text { with the source. Any fault } \\
\text { reports from any of the loads } \\
\text { served by the faulty source are } \\
\text { suppressed. }\end{array}$} & Chiller plant & $\begin{array}{l}\text { 14. If the number of AHUs reporting faults possibly related to the chiller plant is } \\
\text { greater than the threshold and the chiller plant is on, report a possible chiller } \\
\text { plant fault to the operator, and suppress any AHU or terminal unit faults. }\end{array}$ \\
\hline & Boiler plant & $\begin{array}{l}\text { 15. If the number of AHUs reporting faults possibly related to the boiler plant is } \\
\text { greater than the threshold and the boiler plant is on, report a possible boiler } \\
\text { plant fault to the operator, and suppress any AHU or terminal unit faults. }\end{array}$ \\
\hline & Boiler plant & $\begin{array}{l}\text { 16. If the number of terminal units with heating coils reporting faults possibly } \\
\text { related to the boiler plant is greater than the threshold and the boiler plant is } \\
\text { on, report a possible boiler plant fault to the operator, and suppress any } \\
\text { AHU or terminal unit faults. }\end{array}$ \\
\hline & AHU & $\begin{array}{l}\text { 17. If there are no chiller plant or boiler plant faults and the set of terminal units } \\
\text { served by any particular AHU reports a number of faults greater than the } \\
\text { threshold, report a possible AHU fault to the operator, and suppress any } \\
\text { fault reports from the terminal units served by the faulty AHU. }\end{array}$ \\
\hline
\end{tabular}




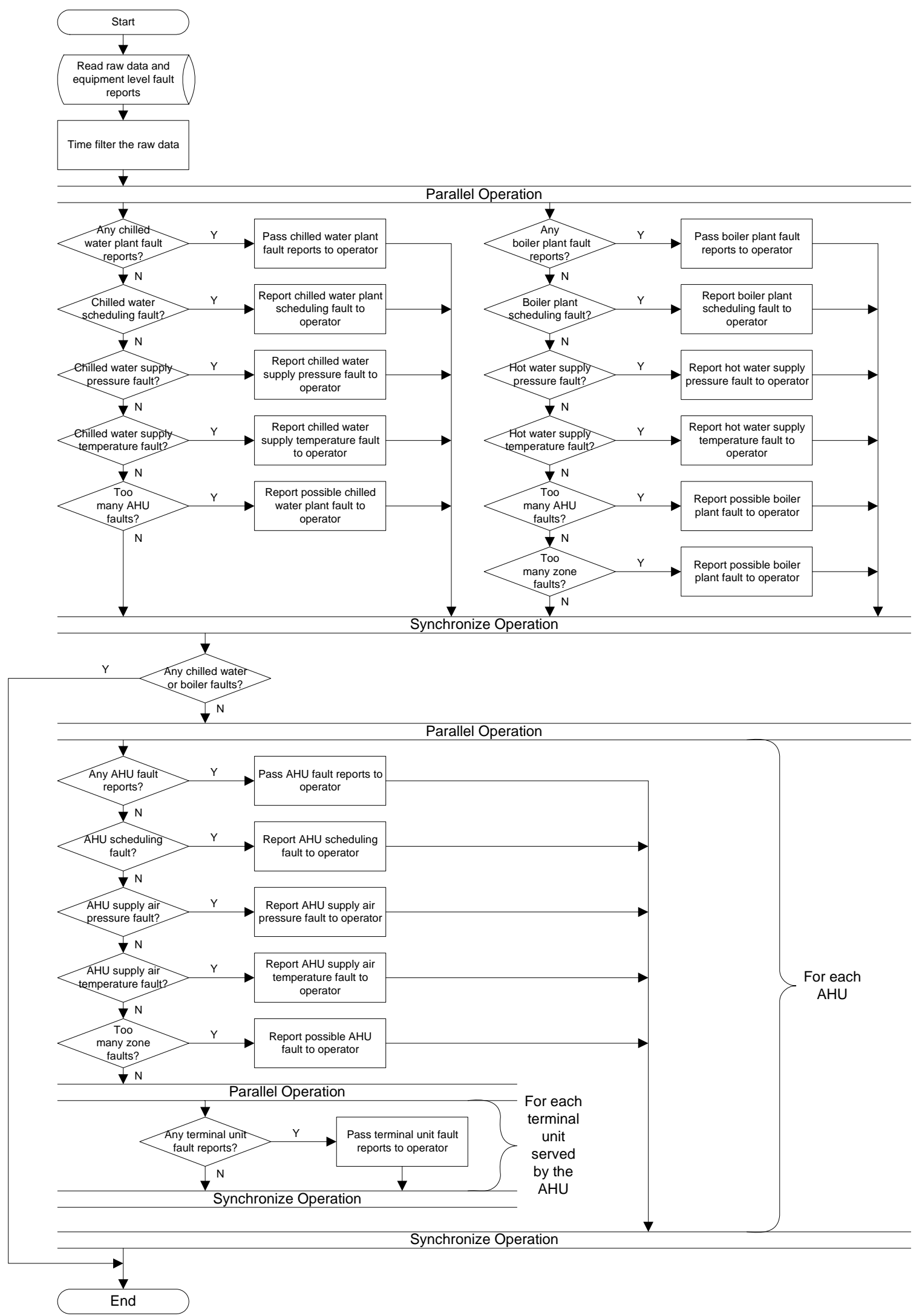

Figure 2. Flowchart of Hierarchical FDD algorithm. 


\section{Testing Environment}

A simulation model of a three-story office building and its HVAC system was developed using the $\mathrm{HVACSIM}^{+}$simulation tool [7]. The simulation consists of nine zones, three air handling units, a chiller, a cooling tower, and a boiler. The terminal units are pressure independent variable-air-volume (VAV) boxes with hydronic reheat. Each of the three single-duct VAV AHUs serves the terminal units for three zones. The building shell and air handling systems are represented by aggregating HVACSIM ${ }^{+}$ component models which were developed in previous research [8]. The chiller and cooling tower models [9] as well as the boiler model [10] were also adapted from previous work. Faults were selected based on their impact on multiple pieces of equipment, in order to provide a meaningful test of the hierarchical FDD algorithm. The faults, listed in Table 2, were simulated through modifications to the boundary conditions or component models.

Table 2. List of HVAC system and equipment faults.

\begin{tabular}{|c|c|c|}
\hline Fault \# & Fault Description & Implementation \\
\hline 0 & Fault free & Run the simulation without modification \\
\hline 1 & AHU scheduling fault & Schedule zone- 1 on during the unoccupied periods \\
\hline 2 & $\begin{array}{l}\text { VAV box reheat coil valve stuck nearly } \\
\text { closed }\end{array}$ & Fix the zone- 1 reheat coil valve position to $5 \%$ open \\
\hline 3 & $\begin{array}{l}\text { VAV box reheat coil valve stuck nearly } \\
\text { open }\end{array}$ & Fix the zone- 1 reheat coil valve position to $95 \%$ open \\
\hline 4 & $\begin{array}{l}\text { VAV box discharge air temperature } \\
\text { sensor fault }\end{array}$ & Fix the zone-1 DAT sensor output to $-10{ }^{\circ} \mathrm{C}$ \\
\hline 5 & Chiller plant scheduling fault & $\begin{array}{l}\text { Schedule AHU-1 and its associated VAV boxes } \\
\text { (zones 1, 4, and 7) on during the unoccupied periods }\end{array}$ \\
\hline 6 & AHU supply air pressure setpoint fault & $\begin{array}{l}\text { Set the AHU-1 supply air pressure setpoint to } \\
0.01 \mathrm{kPa}\end{array}$ \\
\hline 7 & AHU supply air pressure sensor fault & $\begin{array}{l}\text { Fix the AHU-1 supply air pressure sensor output to } \\
-5.00 \mathrm{kPa}\end{array}$ \\
\hline 8 & AHU supply fan failure & Fix the AHU-1 supply fan speed to zero \\
\hline 9 & $\begin{array}{l}\text { AHU supply air temperature setpoint } \\
\text { too low }\end{array}$ & $\begin{array}{l}\text { Change the AHU-1 supply air temperature setpoint to } \\
5^{\circ} \mathrm{C}\end{array}$ \\
\hline 10 & $\begin{array}{l}\text { AHU supply air temperature sensor } \\
\text { drift }\end{array}$ & $\begin{array}{l}\text { Increase the AHU-1 supply air temperature sensor } \\
\text { offset calibration parameter by }+5{ }^{\circ} \mathrm{C}\end{array}$ \\
\hline 11 & $\begin{array}{l}\text { AHU return air temperature sensor } \\
\text { failure }\end{array}$ & $\begin{array}{l}\text { Fix the AHU-1 return air temperature sensor output to } \\
-10^{\circ} \mathrm{C}\end{array}$ \\
\hline 12 & $\begin{array}{l}\text { AHU mixed air temperature sensor } \\
\text { failure }\end{array}$ & $\begin{array}{l}\text { Fix the AHU-1 mixed air temperature sensor output to } \\
-10{ }^{\circ} \mathrm{C}\end{array}$ \\
\hline 13 & $\begin{array}{l}\text { AHU outdoor air temperature sensor } \\
\text { failure }\end{array}$ & $\begin{array}{l}\text { Fix the AHU-1 outdoor air temperature sensor output } \\
\text { to }-20^{\circ} \mathrm{C}\end{array}$ \\
\hline 14 & $\begin{array}{l}\text { AHU heating coil valve stuck nearly } \\
\text { open }\end{array}$ & $\begin{array}{l}\text { Fix the AHU-1 heating coil valve position to } 95 \% \\
\text { open }\end{array}$ \\
\hline 15 & $\begin{array}{l}\text { AHU cooling coil valve stuck nearly } \\
\text { open }\end{array}$ & $\begin{array}{l}\text { Fix the AHU-1 cooling coil valve position to } 95 \% \\
\text { open }\end{array}$ \\
\hline 16 & $\begin{array}{l}\text { Chilled water supply temperature } \\
\text { setpoint fault }\end{array}$ & $\begin{array}{l}\text { Change the chilled water supply temperature setpoint } \\
\text { to } 20^{\circ} \mathrm{C}\end{array}$ \\
\hline 17 & Chilled water supply temperature fault & Fix the chilled water supply temperature to $20^{\circ} \mathrm{C}$ \\
\hline 18 & $\begin{array}{l}\text { Hot water supply temperature setpoint } \\
\text { fault }\end{array}$ & $\begin{array}{l}\text { Change the hot water supply temperature setpoint to } \\
20{ }^{\circ} \mathrm{C}\end{array}$ \\
\hline 19 & Hot water supply temperature fault & Fix the hot water supply temperature to $20^{\circ} \mathrm{C}$ \\
\hline
\end{tabular}




\section{Results}

\section{Overview}

The simulation study consisted of a one-week simulation run for twenty different fault conditions during each of three seasons: heating season (using February weather data), swing season (using October weather data), and cooling season (using July weather data). The simulation output data files were then used as input data for the software implementation of the hierarchical FDD tool. The software implementation also included equipment-specific AHU and VAV box FDD tools which are fully described in [11]. The results are summarized in Table 3. The data were stored and processed using 5 min intervals, so the number of alarms represents the number of 5 min periods during which an alarm was reported. The alarms passed on to the operator by the tool as well as those suppressed by the tool are presented. The actual source of the fault is shaded. The piece of equipment for which the most alarms are passed on to the operator is the primary diagnosis for that simulation run. Any other pieces of equipment for which alarms are passed on to the operator are secondary diagnoses.

For Fault 0 (normal operation) none of the equipment was faulty, nor were any faults reported by the tool. Therefore, the FDD tool gave correct results for all three simulation runs (using cooling, heating, and swing season weather data).

During the Fault 1 simulation runs, Zone 1 was scheduled on during a period when the AHU serving the zone, AHU-1, was scheduled off. This scheduling conflict was detected by Rule 7 of the tool (AHU scheduling conflict) and correctly attributed to AHU-1. Equipment-specific FDD alarms from Zone 1 were correctly suppressed.

Faults 2, 3, and 4 simulated various VAV box mechanical and control faults in Zone 1 that were detected by the equipment-specific VAV box FDD tool and passed on to the operator in accordance with Rule 4 (terminal unit equipment-specific alarm).

During the Fault 5 simulation runs, AHU-1 and its associated VAV boxes (Zones 1, 4, and 7) were scheduled on during a period when the chilled water plant was scheduled off. This scheduling conflict was detected by Rule 5 of the tool (chiller plant scheduling conflict) in cooling and swing seasons. Equipment-specific FDD alarms from AHU-1 and Zones 1, 4, and 7 were correctly suppressed. Rule 5 requires that, in addition to the scheduling inconsistency, there must be a demand for chilled water in order for this fault to exist. The determination of the demand for chilled water includes a delay timer, which is reset upon an AHU mode change. There were three occasions during the cooling season simulation run when a few false alarms from Zone 1 were passed on, because an AHU-1 mode change caused the delay timer to be reset, briefly interrupting the hierarchical FDD tool's suppression of the terminal unit alarms. However, there were many more chilled water plant alarms than terminal unit alarms so the primary diagnosis was the correct one: that the chilled water plant was the source of the fault. During the heating season simulation run there was no demand for chilled water, so no Rule 5 alarms were generated.

In the case of Fault 6, the inappropriate AHU-1 supply air pressure setpoint cannot be detected by the equipment-specific AHU FDD tool. The only way this fault can be detected is to infer an AHU fault due to multiple fault reports from the zones served by the AHU (Rule 17). During cooling and swing seasons, sufficient VAV box faults were reported to the hierarchical FDD tool that the AHU fault was correctly detected in both seasons. The equipment-specific FDD alarms from Zones 1, 4, and 7 were correctly suppressed. However, at certain times during the simulation runs only one of the zones reported a fault to the hierarchical FDD tool, which then incorrectly passed on the VAV box fault, 
causing some false alarms during cooling and swing seasons. For the cooling season, the AHU-1 fault generated more alarms than any of the VAV boxes, so the primary diagnosis was correct. This was not the case for the swing season simulation run. For swing season, the number of Zone 1 alarms was greater than the number of AHU-1 alarms, so the primary diagnosis was incorrect. However, some AHU-1 alarms were reported so the actual cause of the fault did appear as a secondary diagnosis. During heating season, the cooling loads in the zones were low enough that the fault had no impact on system operation, so no VAV box faults were generated which could be used to infer an AHU fault by Rule 17. A more detailed discussion of the results from Fault 6 is presented in the next section.

Faults 7 (AHU-1 supply air pressure sensor failure) and 8 (AHU-1 supply fan failure) were both detected in all three seasons by Rule 13 of the tool, which compares the AHU supply air pressure with the setpoint. All equipment-specific terminal unit alarms were correctly suppressed.

Fault 9 (AHU-1 supply air temperature setpoint too low) was detected in all three seasons by the AHU equipment-specific FDD tool and passed on in accordance with Rule 3. The equipment-specific VAV box FDD tool generated some false alarms for Zone 4, which were suppressed, also in accordance with Rule 3. A more detailed discussion of the results from Fault 9 is presented in the next section.

Fault 10 (AHU-1 supply air temperature sensor drift) was detected in all three seasons by inferring an AHU fault due to multiple fault reports from the zones served by the AHU (Rule 17). False alarms from the VAV box equipment-specific FDD tool were suppressed. Fault 10 was also detected by the equipment-specific AHU FDD tool in swing season.

Faults 11 (AHU-1 return air temperature sensor failure), 12 (AHU-1 mixed air temperature sensor failure), and 13 (AHU-1 outdoor air temperature sensor failure) were detected by the AHU equipmentspecific FDD tool and passed on in accordance with Rule 3. Faults 11 and 12 were detected in all three seasons, while Fault 13 was detected only in cooling and swing seasons. In heating season, Fault 13 had no impact on system operation, therefore no alarms were generated.

Fault 14 (AHU-1 heating coil valve stuck nearly open) was detected by the AHU equipment-specific FDD tool (Rule 3), from a discrepancy between the supply air temperature and the setpoint (Rule 12), and by inferring an AHU fault from multiple zone faults (Rule 17). False alarms from the VAV box equipment-specific FDD tool were suppressed in all three seasons, however, a small number of false alarms were passed on in heating season. The primary diagnosis was correct for all three simulation runs.

Fault 15 (AHU-1 cooling coil valve stuck nearly open) was detected by the AHU equipment-specific FDD tool (Rule 3) and by inferring an AHU fault from multiple zone faults (Rule 17). False alarms from the VAV box equipment-specific FDD tool were suppressed in swing season, however, a small number of false alarms were passed on in heating season. The primary diagnosis was correct for all three simulation runs.

Since there was no central plant FDD tool in this study, the high chilled water supply temperature setpoint fault (Fault 16) was not detected through Rule 1. The fault impacted the operation of the entire system so that the fault was detected by Rule 14 (chiller plant fault inferred due to multiple AHU faults). Most, although not all, of the false alarms from the AHU and VAV box equipment-specific FDD tool were suppressed. For the cooling and swing season simulation runs, the primary diagnosis indicated a chiller plant fault. For the heating season simulation run, the fault did not have as great of an impact on system operation. Although there were faults reported from the equipment-specific FDD tools for AHU- 
1 and AHU-2, they did not occur simultaneously, so there were no alarms generated for the chiller plant by Rule 14. Instead, the false alarms were passed on. Since AHU-2 had the most alarms, it was the primary diagnosis. For the cooling and swing season simulation runs, the primary diagnosis, indicating a chiller plant fault, was correct. For the heating season simulation run, neither the primary nor the secondary diagnosis was correct.

Fault 17, the chilled water supply temperature fault, was correctly diagnosed in all three seasons by Rule 8, which compares the chilled water supply temperature to its setpoint. False alarms from the AHUs and VAV boxes were suppressed, except for one alarm from AHU-3 during cooling season. However, the primary diagnosis was still correct, since there were far more chilled water plant alarms than AHU-3 alarms. A more detailed discussion of the results from Fault 17 is presented in the next section.

Fault 18, the hot water supply temperature setpoint fault can only be detected indirectly through Rules 15 (boiler plant fault inferred due to multiple AHU faults) and 16 (boiler plant fault inferred due to multiple terminal unit faults). Fault 18 does not impact system operation during swing or cooling season so no alarms are generated for those simulation runs. During heating season, equipment-specific faults are reported for AHU-1 and Zone 4 only (because of its exposure, Zone 4 has a higher heating load than the other zones). Since an insufficient number of AHUs or VAV boxes report alarms, neither Rule 15 nor 16 applies, and the equipment-specific FDD alarms are incorrectly passed on to the operator. For the heating season simulation run, neither the primary nor the secondary diagnosis was correct.

Fault 19, the hot water supply temperature fault, was correctly detected by Rule 10, which compares the hot water supply temperature to its setpoint. False alarms from AHU-1 were suppressed.

Of a total of 60 simulation runs, 49 indicated the correct source of the fault as the primary diagnosis. In addition to the three fault-free cases, there were five simulation runs in which the fault had no impact on system operation - in all eight cases the hierarchical FDD tool correctly reported no alarms. In one case, the primary diagnosis was incorrect, but the actual source of the fault was a secondary diagnosis. There were two cases in which the actual source of the fault was neither a primary nor a secondary diagnosis. Combining the 49 correct primary diagnoses with the eight correct non-fault cases, the hierarchical FDD tool provided a correct primary response $95 \%$ of the time. 
Table 3. Results from Simulation.

\begin{tabular}{|c|c|c|c|c|c|c|c|c|c|c|c|c|c|c|c|c|c|}
\hline \multirow{3}{*}{$\begin{array}{l}\text { Fault } \\
\text { ID \# }\end{array}$} & \multirow{3}{*}{ Season } & \multicolumn{14}{|c|}{ \# Alarms Sent to Operator (\# Alarms Suppressed) Note: Actual source of fault is shaded. } & \multirow{3}{*}{$\begin{array}{c}\text { Primary } \\
\text { Diagnosis }\end{array}$} & \multirow{3}{*}{$\begin{array}{c}\text { Primary } \\
\text { Diagnosis } \\
\text { Correct? }\end{array}$} \\
\hline & & \multicolumn{2}{|c|}{ Central Plant } & \multicolumn{4}{|c|}{ Air Handling System 1} & \multicolumn{4}{|c|}{ Air Handling System 2} & \multicolumn{4}{|c|}{ Air Handling System 3} & & \\
\hline & & $\begin{array}{l}\text { Chiller } \\
\text { plant }\end{array}$ & $\begin{array}{l}\text { Boiler } \\
\text { Plant }\end{array}$ & $A H U-1$ & Zone 1 & Zone 4 & Zone 7 & $A H U-2$ & Zone 2 & Zone 5 & Zone 8 & $A H U-3$ & Zone 3 & Zone 6 & Zone 9 & & \\
\hline 0 & Cooling & $0(0)$ & $0(0)$ & $0(0)$ & $0(0)$ & $0(0)$ & $0(0)$ & $0(0)$ & $0(0)$ & $0(0)$ & $0(0)$ & $0(0)$ & $0(0)$ & $0(0)$ & $0(0)$ & None & Yes \\
\hline 0 & Heating & $0(0)$ & $0(0)$ & $0(0)$ & $0(0)$ & $0(0)$ & $0(0)$ & $0(0)$ & $0(0)$ & $0(0)$ & $0(0)$ & $0(0)$ & $0(0)$ & $0(0)$ & $0(0)$ & None & Yes \\
\hline 0 & Swing & $0(0)$ & $0(0)$ & $0(0)$ & $0(0)$ & $0(0)$ & $0(0)$ & $0(0)$ & $0(0)$ & $0(0)$ & $0(0)$ & $0(0)$ & $0(0)$ & $0(0)$ & $0(0)$ & None & Yes \\
\hline 1 & Cooling & $0(0)$ & $0(0)$ & $1475(0)$ & $0(1326)$ & $0(0)$ & $0(0)$ & $0(0)$ & $0(0)$ & $0(0)$ & $0(0)$ & $0(0)$ & $0(0)$ & $0(0)$ & $0(0)$ & AHU-1 & Yes \\
\hline 1 & Heating & $0(0)$ & $0(0)$ & $1475(0)$ & 0 (1112) & $0(0)$ & $0(0)$ & $0(0)$ & $0(0)$ & $0(0)$ & $0(0)$ & $0(0)$ & $0(0)$ & $0(0)$ & $0(0)$ & AHU-1 & Yes \\
\hline 1 & Swing & $0(0)$ & $0(0)$ & $1475(0)$ & 0 (1112) & $0(0)$ & $0(0)$ & $0(0)$ & $0(0)$ & $0(0)$ & $0(0)$ & $0(0)$ & $0(0)$ & $0(0)$ & $0(0)$ & AHU-1 & Yes \\
\hline 2 & Cooling & $0(0)$ & $0(0)$ & $0(0)$ & $158(0)$ & $0(0)$ & $0(0)$ & $0(0)$ & $0(0)$ & $0(0)$ & $0(0)$ & $0(0)$ & $0(0)$ & $0(0)$ & $0(0)$ & Zone 1 & Yes \\
\hline 2 & Heating & $0(0)$ & $0(0)$ & $0(0)$ & $228(0)$ & $0(0)$ & $0(0)$ & $0(0)$ & $0(0)$ & $0(0)$ & $0(0)$ & $0(0)$ & $0(0)$ & $0(0)$ & $0(0)$ & Zone 1 & Yes \\
\hline 2 & Swing & $0(0)$ & $0(0)$ & $0(0)$ & $314(0)$ & $0(0)$ & $0(0)$ & $0(0)$ & $0(0)$ & $0(0)$ & $0(0)$ & $0(0)$ & $0(0)$ & $0(0)$ & $0(0)$ & Zone 1 & Yes \\
\hline 3 & Cooling & $0(0)$ & $0(0)$ & $0(0)$ & $581(36)$ & $0(0)$ & $0(0)$ & $0(0)$ & $0(0)$ & $0(0)$ & $0(0)$ & $0(0)$ & $0(0)$ & $0(0)$ & $0(0)$ & Zone 1 & Yes \\
\hline 3 & Heating & $0(0)$ & $0(0)$ & $0(0)$ & $581(28)$ & $0(0)$ & $0(0)$ & $0(0)$ & $0(0)$ & $0(0)$ & $0(0)$ & $0(0)$ & $0(0)$ & $0(0)$ & $0(0)$ & Zone 1 & Yes \\
\hline 3 & Swing & $0(0)$ & $0(0)$ & $0(0)$ & $581(33)$ & $0(0)$ & $0(0)$ & $0(0)$ & $0(0)$ & $0(0)$ & $0(0)$ & $0(0)$ & $0(0)$ & $0(0)$ & $0(0)$ & Zone 1 & Yes \\
\hline 4 & Cooling & $0(0)$ & $0(0)$ & $0(0)$ & $581(70)$ & $0(0)$ & $0(0)$ & $0(0)$ & $0(0)$ & $0(0)$ & $0(0)$ & $0(0)$ & $0(0)$ & $0(0)$ & $0(0)$ & Zone 1 & Yes \\
\hline 4 & Swing & $0(0)$ & $0(0)$ & $0(0)$ & $581(69)$ & $0(0)$ & $0(0)$ & $0(0)$ & $0(0)$ & $0(0)$ & $0(0)$ & $0(0)$ & $0(0)$ & $0(0)$ & $0(0)$ & Zone 1 & Yes \\
\hline 5 & Cooling & $1450(0)$ & $0(0)$ & $0(1260)$ & $8(1120)$ & $0(140)$ & $0(119)$ & $0(0)$ & $0(0)$ & $0(0)$ & $0(0)$ & $0(0)$ & $0(0)$ & $0(0)$ & $0(0)$ & Chiller & Yes \\
\hline 5 & Heating & $0(0)$ & $0(0)$ & $0(0)$ & $0(0)$ & $0(0)$ & $0(0)$ & $0(0)$ & $0(0)$ & $0(0)$ & $0(0)$ & $0(0)$ & $0(0)$ & $0(0)$ & $0(0)$ & None & Yes \\
\hline 5 & Swing & $807(0)$ & $0(0)$ & 0 (587) & $0(140)$ & 0 (114) & $0(100)$ & $0(0)$ & $0(0)$ & $0(0)$ & $0(0)$ & $0(0)$ & $0(0)$ & $0(0)$ & $0(0)$ & Chiller & Yes \\
\hline 6 & Cooling & $0(0)$ & $0(0)$ & $264(0)$ & $0(130)$ & 75 (264) & $51(263)$ & $0(0)$ & $0(0)$ & $0(0)$ & $0(0)$ & $0(0)$ & $0(0)$ & $0(0)$ & $0(0)$ & AHU-1 & Yes \\
\hline 6 & Heating & $0(0)$ & $0(0)$ & $0(0)$ & $0(0)$ & $0(0)$ & $0(0)$ & $0(0)$ & $0(0)$ & $0(0)$ & $0(0)$ & $0(0)$ & $0(0)$ & $0(0)$ & $0(0)$ & None & Yes \\
\hline 6 & Swing & $0(0)$ & $0(0)$ & $32(0)$ & $40(28)$ & $0(8)$ & $1(32)$ & $0(0)$ & $0(0)$ & $0(0)$ & $0(0)$ & $0(0)$ & $0(0)$ & $0(0)$ & $0(0)$ & Zone 1 & No \\
\hline 7 & Cooling & $0(0)$ & $0(0)$ & $581(0)$ & $0(0)$ & $0(0)$ & $0(0)$ & $0(0)$ & $0(0)$ & $0(0)$ & $0(0)$ & $0(0)$ & $0(0)$ & $0(0)$ & $0(0)$ & AHU-1 & Yes \\
\hline 7 & Heating & $0(0)$ & $0(0)$ & $581(0)$ & $0(0)$ & $0(0)$ & $0(0)$ & $0(0)$ & $0(0)$ & $0(0)$ & $0(0)$ & $0(0)$ & $0(0)$ & $0(0)$ & $0(0)$ & AHU-1 & Yes \\
\hline 7 & Swing & $0(0)$ & $0(0)$ & $581(0)$ & $0(0)$ & $0(0)$ & $0(0)$ & $0(0)$ & $0(0)$ & $0(0)$ & $0(0)$ & $0(0)$ & $0(0)$ & $0(0)$ & $0(0)$ & AHU-1 & Yes \\
\hline 8 & Cooling & $0(0)$ & $0(0)$ & $581(0)$ & $0(145)$ & $0(362)$ & 0 (345) & $0(0)$ & $0(0)$ & $0(0)$ & $0(0)$ & $0(0)$ & $0(0)$ & $0(0)$ & $0(0)$ & AHU-1 & Yes \\
\hline 8 & Heating & $0(0)$ & $0(0)$ & $581(0)$ & $0(0)$ & $0(0)$ & $0(0)$ & $0(0)$ & $0(0)$ & $0(0)$ & $0(0)$ & $0(0)$ & $0(0)$ & $0(0)$ & $0(0)$ & AHU-1 & Yes \\
\hline 8 & Swing & $0(0)$ & $0(0)$ & $581(0)$ & $0(54)$ & $0(25)$ & $0(94)$ & $0(0)$ & $0(0)$ & $0(0)$ & $0(0)$ & $0(0)$ & $0(0)$ & $0(0)$ & $0(0)$ & AHU-1 & Yes \\
\hline 9 & Cooling & $0(0)$ & $0(0)$ & $451(0)$ & $0(0)$ & $0(0)$ & $0(0)$ & $0(0)$ & $0(0)$ & $0(0)$ & $0(0)$ & $0(0)$ & $0(0)$ & $0(0)$ & $0(0)$ & AHU-1 & Yes \\
\hline 9 & Heating & $0(0)$ & $0(0)$ & $506(0)$ & $0(0)$ & $0(44)$ & $0(0)$ & $0(0)$ & $0(0)$ & $0(0)$ & $0(0)$ & $0(0)$ & $0(0)$ & $0(0)$ & $0(0)$ & AHU-1 & Yes \\
\hline
\end{tabular}


Table 3. (continued)

\begin{tabular}{|c|c|c|c|c|c|c|c|c|c|c|c|c|c|c|c|c|c|}
\hline \multirow{3}{*}{$\begin{array}{l}\text { Fault } \\
\text { ID \# }\end{array}$} & \multirow{3}{*}{ Season } & \multicolumn{14}{|c|}{ \# Alarms Sent to Operator (\# Alarms Suppressed) Note: Actual source of fault is shaded. } & \multirow{3}{*}{$\begin{array}{c}\text { Primary } \\
\text { Diagnosis }\end{array}$} & \multirow{3}{*}{$\begin{array}{c}\text { Primary } \\
\text { Diagnosis } \\
\text { Correct? }\end{array}$} \\
\hline & & \multicolumn{2}{|c|}{ Central Plant } & \multicolumn{4}{|c|}{ Air Handling System 1} & \multicolumn{4}{|c|}{ Air Handling System 2} & \multicolumn{4}{|c|}{ Air Handling System 3} & & \\
\hline & & $\begin{array}{l}\text { Chiller } \\
\text { plant }\end{array}$ & $\begin{array}{l}\text { Boiler } \\
\text { Plant }\end{array}$ & $A H U-1$ & Zone 1 & Zone 4 & Zone 7 & AHU-2 & Zone 2 & Zone 5 & Zone 8 & $A H U-3$ & Zone 3 & Zone 6 & Zone 9 & & \\
\hline 10 & Cooling & $0(0)$ & $0(0)$ & $497(0)$ & $0(497)$ & $0(497)$ & $0(497)$ & $0(0)$ & $0(0)$ & $0(0)$ & $0(0)$ & $0(0)$ & $0(0)$ & $0(0)$ & $0(0)$ & AHU-1 & Yes \\
\hline 10 & Heating & $0(0)$ & $0(0)$ & $510(0)$ & $0(497)$ & $0(497)$ & 0 (495) & $0(0)$ & $0(0)$ & $0(0)$ & $0(0)$ & $0(0)$ & $0(0)$ & $0(0)$ & $0(0)$ & $\mathrm{AHU}-1$ & Yes \\
\hline 10 & Swing & $0(0)$ & $0(0)$ & $507(0)$ & $0(497)$ & $0(497)$ & 0 (497) & $0(0)$ & $0(0)$ & $0(0)$ & $0(0)$ & $0(0)$ & $0(0)$ & $0(0)$ & $0(0)$ & AHU-1 & Yes \\
\hline 11 & Cooling & $0(0)$ & $0(0)$ & $438(0)$ & $0(0)$ & $0(0)$ & $0(0)$ & $0(0)$ & $0(0)$ & $0(0)$ & $0(0)$ & $0(0)$ & $0(0)$ & $0(0)$ & $0(0)$ & AHU-1 & Yes \\
\hline 11 & Heating & $0(0)$ & $0(0)$ & $507(0)$ & $0(0)$ & $0(0)$ & $0(0)$ & $0(0)$ & $0(0)$ & $0(0)$ & $0(0)$ & $0(0)$ & $0(0)$ & $0(0)$ & $0(0)$ & $\mathrm{AHU}-1$ & Yes \\
\hline 11 & Swing & $0(0)$ & $0(0)$ & $234(0)$ & $0(0)$ & $0(0)$ & $0(0)$ & $0(0)$ & $0(0)$ & $0(0)$ & $0(0)$ & $0(0)$ & $0(0)$ & $0(0)$ & $0(0)$ & AHU-1 & Yes \\
\hline 12 & Cooling & $0(0)$ & $0(0)$ & $479(0)$ & $0(0)$ & $0(0)$ & $0(0)$ & $0(0)$ & $0(0)$ & $0(0)$ & $0(0)$ & $0(0)$ & $0(0)$ & $0(0)$ & $0(0)$ & AHU-1 & Yes \\
\hline 12 & Heating & $0(0)$ & $0(0)$ & $485(0)$ & $0(0)$ & $0(0)$ & $0(0)$ & $0(0)$ & $0(0)$ & $0(0)$ & $0(0)$ & $0(0)$ & $0(0)$ & $0(0)$ & $0(0)$ & AHU-1 & Yes \\
\hline 12 & Swing & $0(0)$ & $0(0)$ & $407(0)$ & $0(0)$ & $0(0)$ & $0(0)$ & $0(0)$ & $0(0)$ & $0(0)$ & $0(0)$ & $0(0)$ & $0(0)$ & $0(0)$ & $0(0)$ & AHU-1 & Yes \\
\hline 13 & Cooling & $0(0)$ & $0(0)$ & $447(0)$ & $0(0)$ & $0(0)$ & $0(0)$ & $0(0)$ & $0(0)$ & $0(0)$ & $0(0)$ & $0(0)$ & $0(0)$ & $0(0)$ & $0(0)$ & AHU-1 & Yes \\
\hline 13 & Heating & $0(0)$ & $0(0)$ & $0(0)$ & $0(0)$ & $0(0)$ & $0(0)$ & $0(0)$ & $0(0)$ & $0(0)$ & $0(0)$ & $0(0)$ & $0(0)$ & $0(0)$ & $0(0)$ & None & Yes \\
\hline 13 & Swing & $0(0)$ & $0(0)$ & $81(0)$ & $0(0)$ & $0(0)$ & $0(0)$ & $0(0)$ & $0(0)$ & $0(0)$ & $0(0)$ & $0(0)$ & $0(0)$ & $0(0)$ & $0(0)$ & AHU-1 & Yes \\
\hline 14 & Cooling & $0(0)$ & $0(0)$ & $654(0)$ & $0(654)$ & $0(654)$ & $0(655)$ & $0(0)$ & $0(0)$ & $0(0)$ & $0(0)$ & $0(0)$ & $0(0)$ & $0(0)$ & $0(0)$ & AHU-1 & Yes \\
\hline 14 & Heating & $0(0)$ & $0(0)$ & $563(0)$ & $2(399)$ & $0(358)$ & 0 (394) & $0(0)$ & $0(0)$ & $0(0)$ & $0(0)$ & $0(0)$ & $0(0)$ & $0(0)$ & $0(0)$ & AHU-1 & Yes \\
\hline 14 & Swing & $0(0)$ & $0(0)$ & $484(0)$ & $0(318)$ & $0(319)$ & $0(318)$ & $0(0)$ & $0(0)$ & $0(0)$ & $0(0)$ & $0(0)$ & $0(0)$ & $0(0)$ & $0(0)$ & AHU-1 & Yes \\
\hline 15 & Cooling & $0(0)$ & $0(0)$ & $1(0)$ & $0(0)$ & $0(0)$ & $0(0)$ & $0(0)$ & $0(0)$ & $0(0)$ & $0(0)$ & $0(0)$ & $0(0)$ & $0(0)$ & $0(0)$ & AHU-1 & Yes \\
\hline 15 & Heating & $0(0)$ & $0(0)$ & $55(0)$ & $2(0)$ & $0(0)$ & $0(0)$ & $0(0)$ & $0(0)$ & $0(0)$ & $0(0)$ & $0(0)$ & $0(0)$ & $0(0)$ & $0(0)$ & AHU-1 & Yes \\
\hline 15 & Swing & $0(0)$ & $0(0)$ & $14(0)$ & $0(2)$ & $0(0)$ & $0(2)$ & $0(0)$ & $0(0)$ & $0(0)$ & $0(0)$ & $0(0)$ & $0(0)$ & $0(0)$ & $0(0)$ & AHU-1 & Yes \\
\hline 16 & Cooling & $495(0)$ & $0(0)$ & $36(462)$ & $0(220)$ & $0(231)$ & $2(227)$ & $56(495)$ & $0(448)$ & $0(500)$ & $8(502)$ & 69 (492) & $0(481)$ & $3(531)$ & $0(521)$ & Chiller & Yes \\
\hline 16 & Heating & $0(0)$ & $0(0)$ & $1(0)$ & $0(0)$ & $0(0)$ & $0(0)$ & $25(0)$ & $0(0)$ & $0(0)$ & $0(0)$ & $0(0)$ & $0(0)$ & $0(0)$ & $0(0)$ & AHU-2 & No \\
\hline 16 & Swing & $301(0)$ & $0(0)$ & $4(285)$ & $0(0)$ & $0(0)$ & $0(0)$ & $28(300)$ & $0(9)$ & $0(28)$ & $0(16)$ & 59 (301) & $0(63)$ & 0 (122) & $0(53)$ & Chiller & Yes \\
\hline 17 & Cooling & $581(0)$ & $0(0)$ & $0(477)$ & $0(71)$ & $0(208)$ & 0 (148) & 0 (493) & $0(467)$ & $0(514)$ & $0(523)$ & $1(489)$ & 0 (494) & 0 (544) & $0(536)$ & Chiller & Yes \\
\hline 17 & Heating & $581(0)$ & $0(0)$ & $0(1)$ & $0(0)$ & $0(0)$ & $0(0)$ & $0(8)$ & $0(0)$ & $0(0)$ & $0(0)$ & $0(0)$ & $0(0)$ & $0(0)$ & $0(0)$ & Chiller & Yes \\
\hline 17 & Swing & $581(0)$ & $0(0)$ & $0(358)$ & $0(0)$ & $0(0)$ & $0(0)$ & $0(423)$ & $0(81)$ & $0(85)$ & $0(61)$ & $0(427)$ & 0 (120) & 0 (178) & 0 (129) & Chiller & Yes \\
\hline 18 & Cooling & $0(0)$ & $0(0)$ & $0(0)$ & $0(0)$ & $0(0)$ & $0(0)$ & $0(0)$ & $0(0)$ & $0(0)$ & $0(0)$ & $0(0)$ & $0(0)$ & $0(0)$ & $0(0)$ & None & Yes \\
\hline 18 & Heating & $0(0)$ & $0(0)$ & $18(0)$ & $0(0)$ & 337 (18) & $0(0)$ & $0(0)$ & $0(0)$ & $0(0)$ & $0(0)$ & $0(0)$ & $0(0)$ & $0(0)$ & $0(0)$ & Zone 4 & No \\
\hline 18 & Swing & $0(0)$ & $0(0)$ & $0(0)$ & $0(0)$ & $0(0)$ & $0(0)$ & $0(0)$ & $0(0)$ & $0(0)$ & $0(0)$ & $0(0)$ & $0(0)$ & $0(0)$ & $0(0)$ & None & Yes \\
\hline 19 & Cooling & $0(0)$ & $581(0)$ & $0(0)$ & $0(0)$ & $0(0)$ & $0(0)$ & $0(0)$ & $0(0)$ & $0(0)$ & $0(0)$ & $0(0)$ & $0(0)$ & $0(0)$ & $0(0)$ & Boiler & Yes \\
\hline 19 & Heating & $0(0)$ & $581(0)$ & 0 (18) & $0(0)$ & $0(355)$ & $0(0)$ & $0(0)$ & $0(0)$ & $0(0)$ & $0(0)$ & $0(0)$ & $0(0)$ & $0(0)$ & $0(0)$ & Boiler & Yes \\
\hline 19 & Swing & $0(0)$ & $581(0)$ & $0(0)$ & $0(0)$ & $0(0)$ & $0(0)$ & $0(0)$ & $0(0)$ & $0(0)$ & $0(0)$ & $0(0)$ & $0(0)$ & $0(0)$ & $0(0)$ & Boiler & Yes \\
\hline
\end{tabular}




\section{Air Handling Unit Supply Air Temperature Setpoint Too Low}

The heating season simulation of Fault 9 illustrates the principle that fault reports from a load are suppressed if there are any fault reports from a source serving that load.

In the fault free simulation, the supply air temperature setpoint is reset based on the zone temperatures of the spaces served by the AHU. The fault was implemented by replacing the reset schedule for AHU- 1 with a fixed value of $5{ }^{\circ} \mathrm{C}$, which is less than the $10{ }^{\circ} \mathrm{C}$ minimum value in the reset schedule.

Figure 3 shows the results from the occupied period of one day of the simulation. On this day, the supply air temperature could only be maintained at the new setpoint by keeping the cooling coil valve fully open for the entire day. This condition was detected as a fault by the equipment-specific AHU FDD, which generated an alarm and sent it to the hierarchical FDD tool.

Figure 4 shows the effect of Fault 9 on Zone 4 for the same time period as in Figure 3. Since there was a heating load on the zone, the VAV box damper closed as far as possible given its minimum airflow requirement, while the reheat coil valve opened fully. The air supplied to the VAV box by AHU-1 was so cold that even with the minimum airflow and maximum reheat, the zone temperature remained below the heating setpoint. Due to the low zone temperature, the equipment-specific VAV box FDD generated an alarm and sent it to the hierarchical FDD tool.

The hierarchical FDD tool received the equipment-specific FDD fault reports from both AHU-1 and Zone 4. Rule 3 states that if there are any equipment-level AHU faults, they are passed on to the operator, and any fault reports from the terminal units served by the faulty AHU are suppressed. In accordance with Rule 3, the AHU-1 fault report was correctly passed on to the operator, while the Zone 4 fault report was correctly suppressed. 


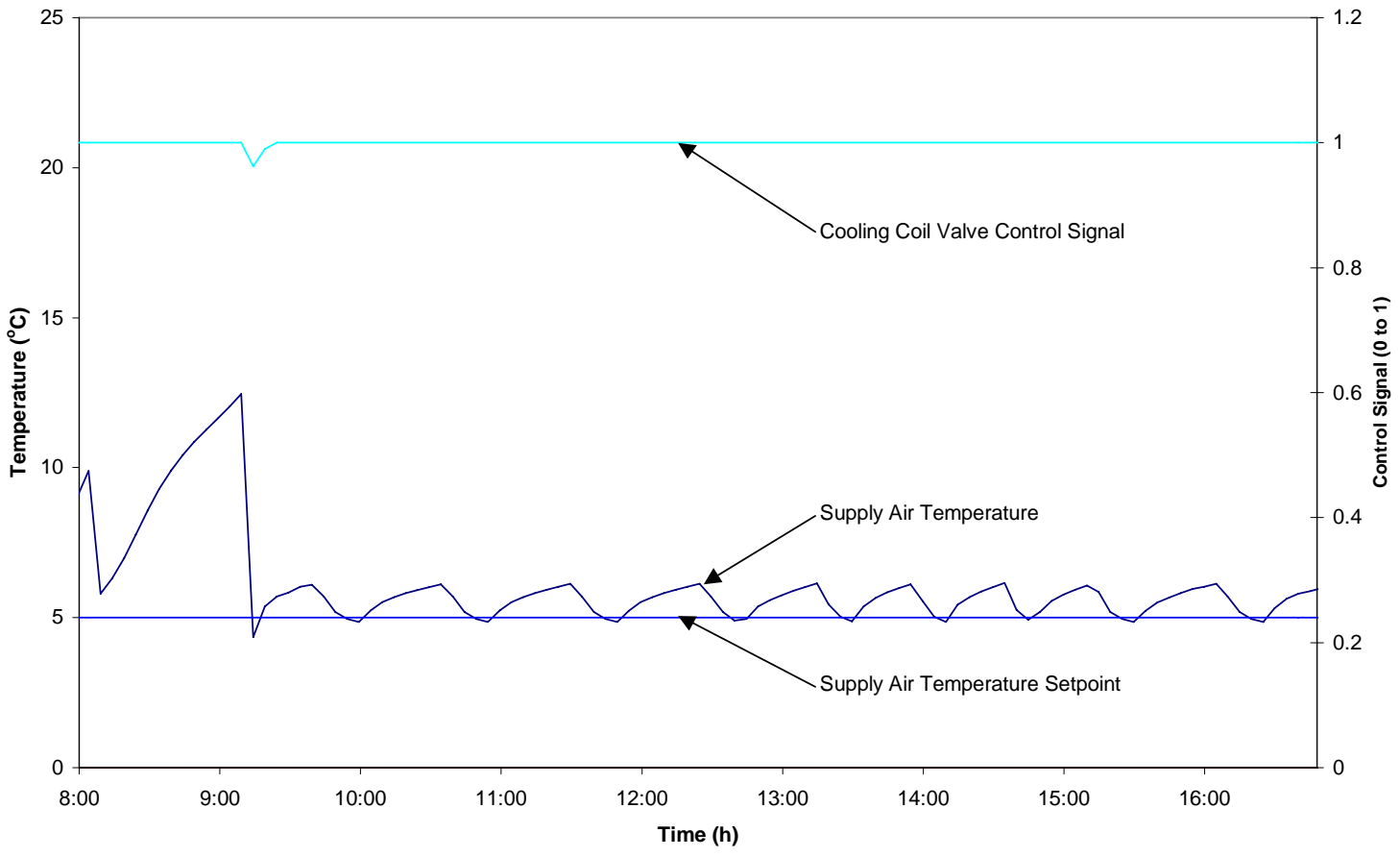

Figure 3. Fault 9, AHU supply air temperature setpoint too low, heating season. AHU-1 temperature and control signal data.

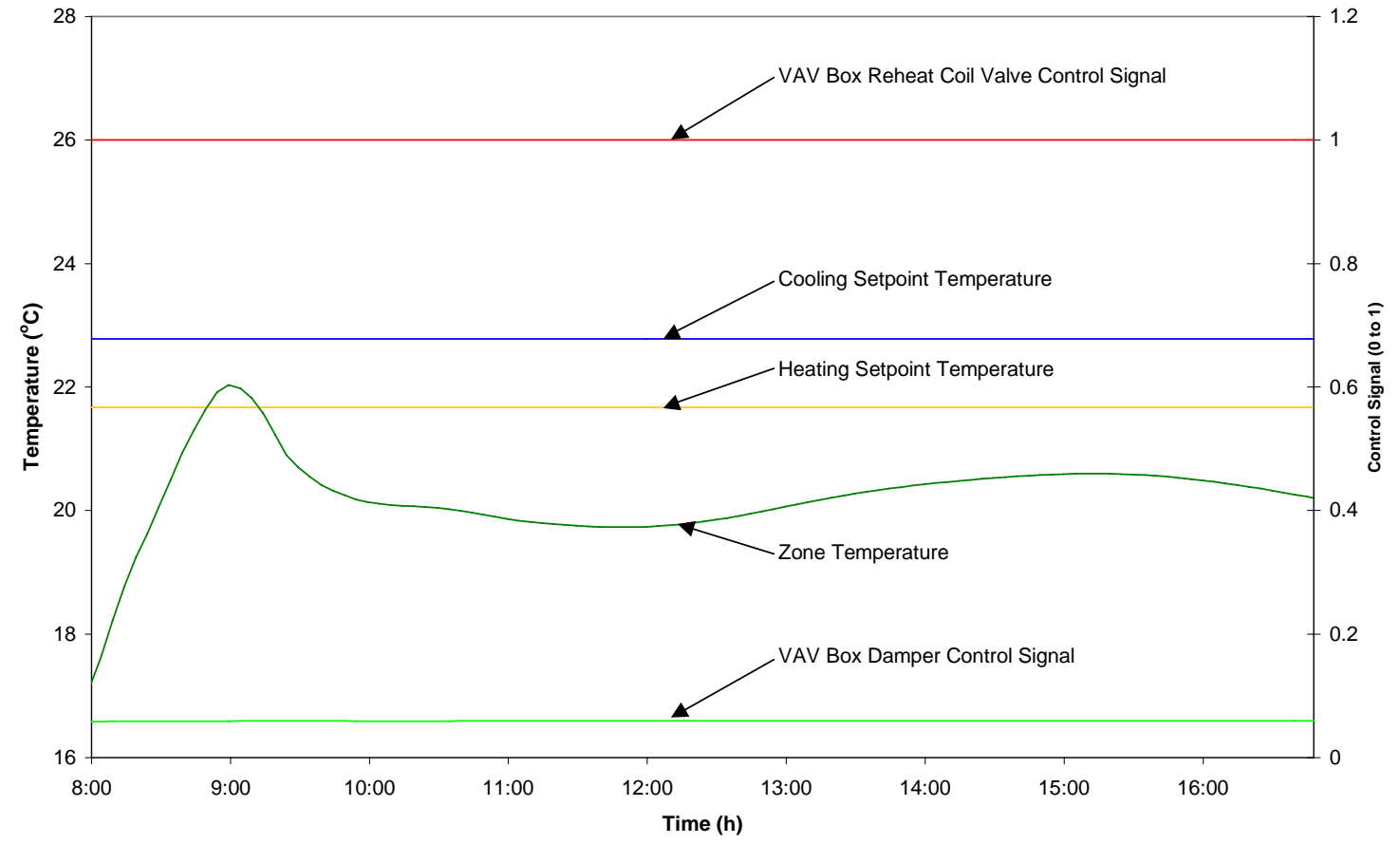

Figure 4. Fault 9, AHU supply air temperature setpoint too low, heating season. Zone 4 temperature and control signal data. 


\section{Chilled Water Supply Temperature Fault}

Fault 17, the chilled water supply temperature fault, provides a good example of the principle that a fault in the air or water interface between a source and the loads it serves is considered a fault associated with the source. The fault was implemented by fixing the chilled water supply temperature in the simulation model to a constant value of $20^{\circ} \mathrm{C}$ (the setpoint is $6^{\circ} \mathrm{C}$ ). There was no equipment-specific chilled water plant FDD tool in this study, so no fault report was sent to the hierarchical FDD tool.

Chilled water is supplied from the central plant to AHU-1, AHU-2, and AHU-3. Figure 5 shows the effect of this fault on AHU-3 from the occupied period of one day of the simulation; the results for AHU-1 and AHU-2 are similar. The AHU control logic modulates the cooling coil control valve to maintain the supply air temperature at its setpoint. Because the chilled water supplied to the AHU cooling coil was too warm, the cooling coil valve saturated at $100 \%$ open, while the supply air temperature remained well above its setpoint. The equipment-specific AHU FDD tool detected the presence of a fault and sent a fault report to the hierarchical FDD tool.

The cascading effects of the fault can also be seen in the VAV boxes that are supplied with conditioned air from the AHUs. Results for Zone 3 are shown in Figure 6 (same time period as Figure 5); the results are typical for six of the nine zones in the simulation. The supply air temperature was too warm to maintain the zone air temperature at the cooling setpoint. The equipment-specific VAV box FDD generated a fault report and sent it to the hierarchical FDD tool.

Rule 8 implements the principle that a fault in the air or water interface between a source and the loads it serves is considered a fault associated with the source, specifically for the chiller plant - AHU relationship. The rule states that if the chilled water supply temperature is greater than its setpoint by more than a threshold amount, then a chilled water plant fault is reported and any AHU or terminal unit fault reports are suppressed. In this case, the difference between the chilled water supply temperature and the setpoint was greater than the threshold value $\left(10^{\circ} \mathrm{C}\right)$, so a chilled water plant fault was correctly reported, while at the same time the AHU and VAV box fault reports were correctly suppressed. The relatively severe faults selected for this study were chosen to maximize their impact on multiple pieces of equipment, in order to have a more meaningful test of the hierarchical FDD tool. 


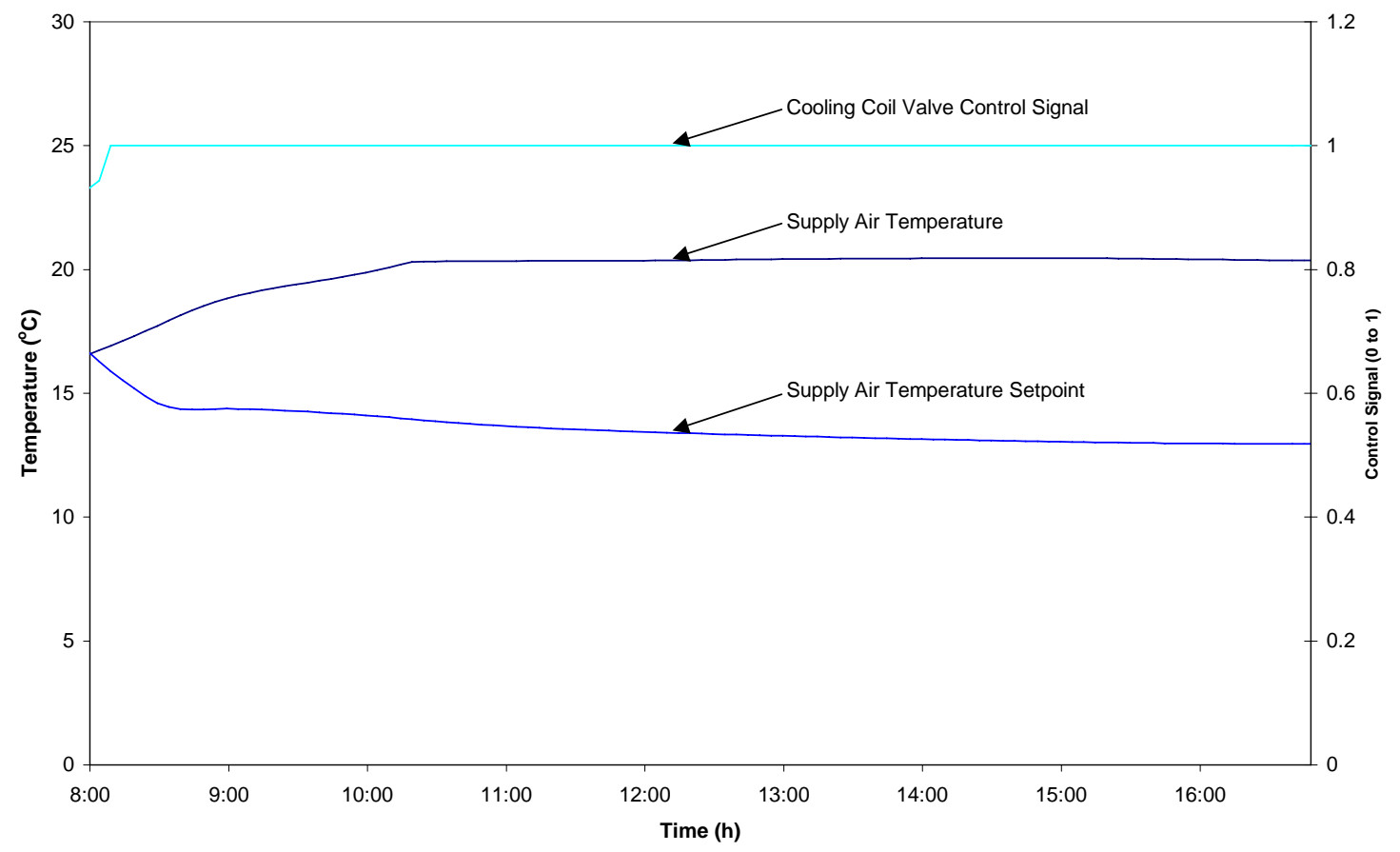

Figure 5. Fault 17, chilled water supply temperature fault, swing season. AHU-3 temperature and control signal data.

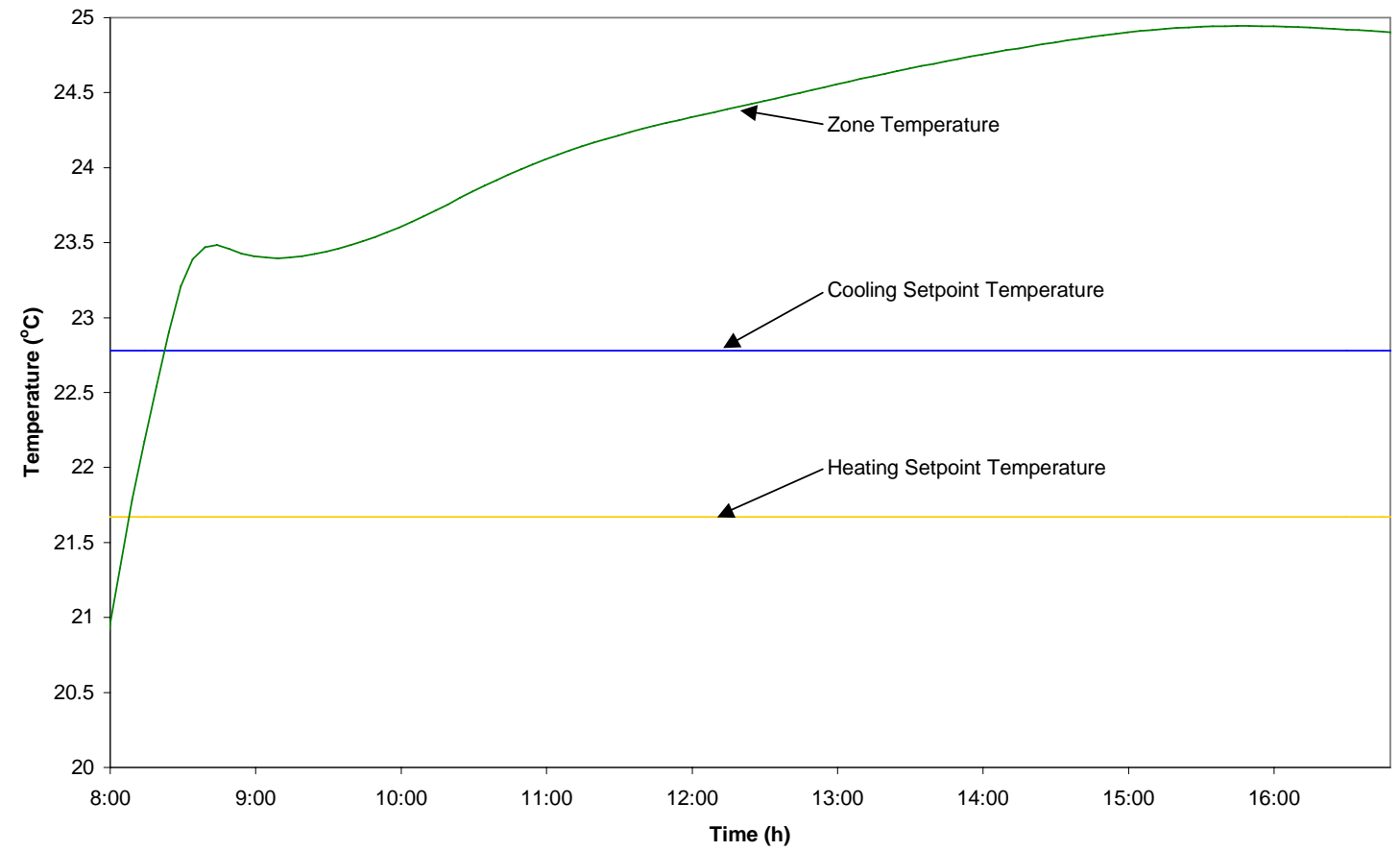

Figure 6. Fault 17, chilled water supply temperature fault, swing season. Zone 3 temperature data. 


\section{Air Handling Unit Supply Air Pressure Setpoint Too Low}

Fault 6, the AHU supply air pressure fault, provides a good example of the principle that multiple fault reports from the loads served by a source are a fault associated with the source. The fault was implemented in the simulation by changing the AHU-1 supply air pressure setpoint from $0.25 \mathrm{kPa}$ to $0.01 \mathrm{kPa}$. The AHU control logic modulates the supply fan speed to maintain the supply air pressure at the setpoint, so no fault was detected by the equipment-specific AHU FDD tool.

The effect of this fault on Zone 1 for the occupied period of one day of the simulation is shown in Figures 7 and 8. The effects on Zones 4 and 7 (the other zones served by AHU1) are similar. When occupancy began, the cooling load, zone temperature, and airflow setpoint all increased. Figure 7 shows that, because the supply air pressure was too low, the actual airflow fell well below the setpoint while the VAV box damper saturated fully open. Figure 8 shows that, as a result, the zone temperature rose above the cooling setpoint. The equipment-specific VAV box FDD tool generated fault reports due to the difference between the zone airflow rate and setpoint as well as the difference between the zone temperature and the cooling setpoint.

In order for the hierarchical FDD tool to interpret multiple VAV box faults as an AHU fault, the VAV box faults must occur simultaneously. Specifically in the case of this study, at least two of the three zones must report faults simultaneously for an AHU fault report to be generated. In general, the equipment-specific FDD tool for each VAV box will not report faults at exactly the same time, so some false alarms occurred. For example, for the day shown in Figures 7 and 8, the Zone 4 VAV box FDD tool reported a fault from 15:10 until 17:00 (the end of occupancy) while Zone 4 reported a fault from 15:25 until 17:00 and Zone 7 reported a fault from 15:30 until 17:00. From 15:10 until $15: 25$, there was only one VAV box reporting a fault, so the incorrect VAV box fault report was passed on by the hierarchical FDD tool. From 15:25 until 17:00, there were at least two VAV boxes reporting faults, so the hierarchical FDD tool correctly suppressed the VAV box fault report and generated an AHU fault report. The primary diagnosis for this day of the simulation is the correct AHU fault. 


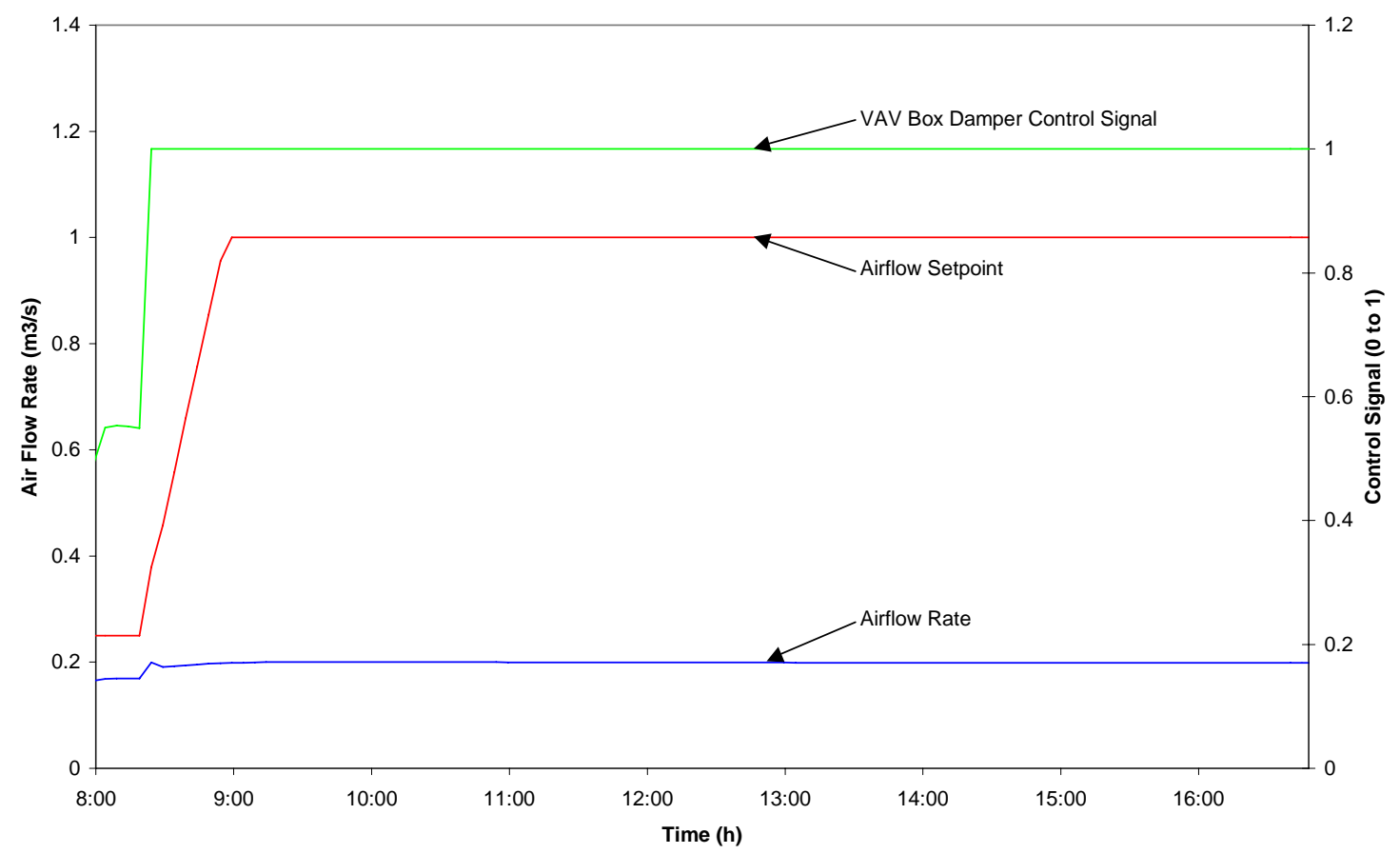

Figure 7. Fault 6, AHU supply air pressure setpoint fault, cooling season. Zone 1 airflow and control signal data.

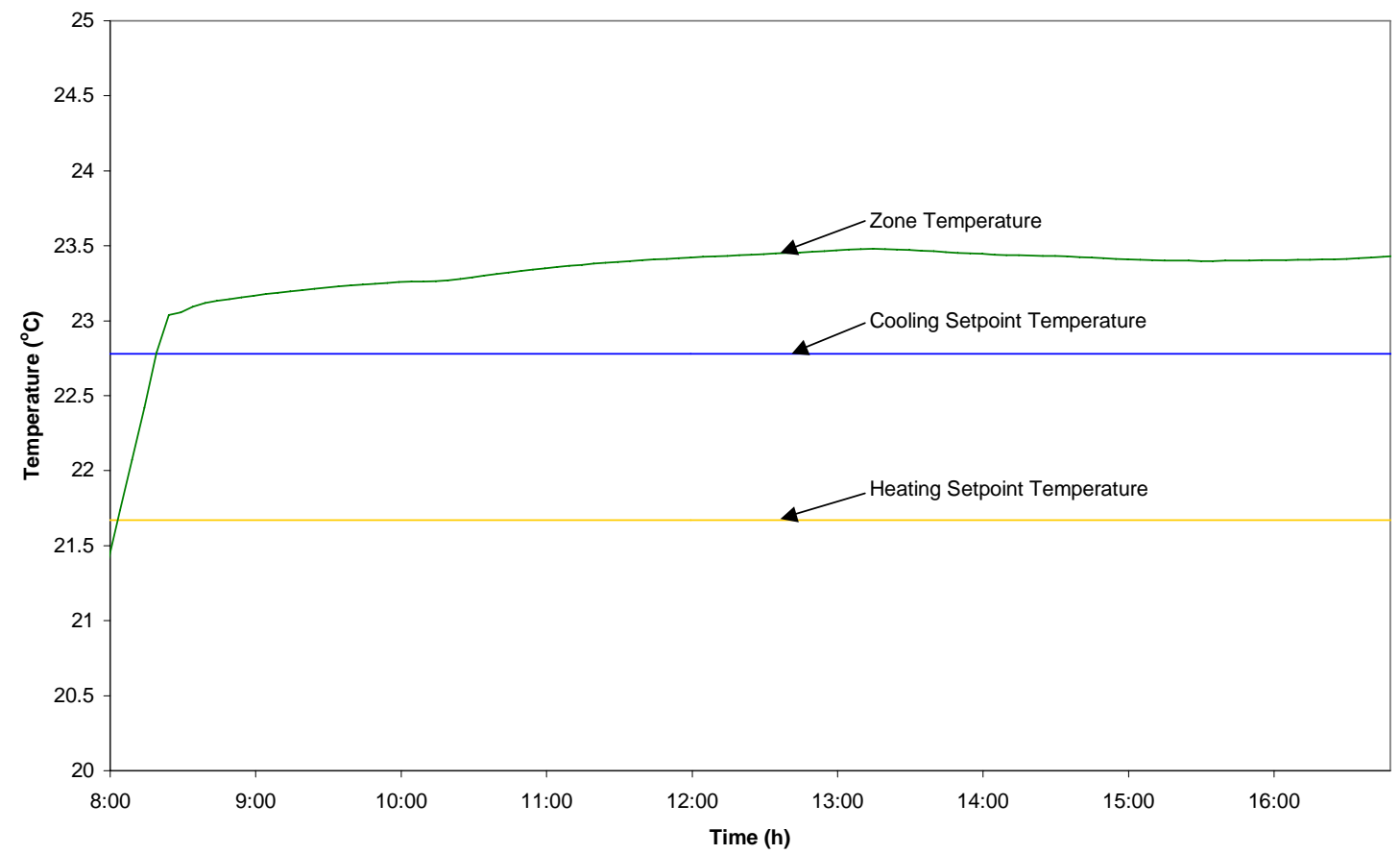

Figure 8. Fault 6, AHU supply air pressure setpoint fault, cooling season. Zone 1 temperature data. 


\section{Conclusions and Future Work}

A system-level hierarchical FDD tool was developed and a simulation study to test and evaluate the tool was conducted. In general, the results were positive: the tool's primary diagnosis was correct for 57 of 60 simulation runs (95\%). In one case, the primary diagnosis was incorrect, but the actual source of the fault was a secondary diagnosis. There were two cases in which the actual source of the fault was neither a primary nor a secondary diagnosis. The hierarchical FDD tool was shown to effectively filter equipment-level fault reports and detect and diagnose system-level faults.

The results from the simulation study, while promising, suggest some refinements to the hierarchical FDD tool, particularly the ability to infer a higher level fault from multiple lower level fault reports that occur close to the same time, but are not simultaneous. Another enhancement might be the ability to handle multiple, unrelated faults which may cause the hierarchical FDD tool to suppress real fault reports from lower levels in the hierarchy while correctly reporting higher level faults.

The next step will be to refine the hierarchical FDD tool and conduct another simulation study. Future work will include further testing and refinement by collecting trend data from building control systems at field sites. Implementations of the FDD tool will then be developed for several different control system manufacturers' product architectures. Testing in an emulation or laboratory setting will validate the implementations. Finally, a larger scale field test of the embedded implementations of the tool will be conducted to serve as a demonstration project in order to transition the tool from research to the marketplace. 


\section{References}

[1] Dexter A. and Pakanen, J. (Ed.). 2001. International Energy Agency:

Demonstrating Automated Fault Detection and Diagnosis in Real Buildings. Published

by Technical Research Centre of Finland, Laboratory of Heating and Ventilation, Espoo, Finland.

[2] Hyvärinen, J. and Kärki, S. (Ed.). 1996. International Energy Agency Building Optimisation and Fault Diagnosis Source Book. Published by Technical Research Centre of Finland, Laboratory of Heating and Ventilation, Espoo, Finland.

[3] Schein, J., Bushby, S.T., Castro, N.S., House, J.M. 2003. "Results from Field Testing of Air Handling Unit and Variable Air Volume Box Diagnostic Tools,” NISTIR 6994. National Institute of Standards and Technology. Gaithersburg, MD.

[4] Bonarini, A. and Sassaroli, P. 1997. "Opportunistic Multimodel Diagnosis with Imperfect Models,” Information Sciences, Vol. 103, pp. 161-185.

[5] Ross, S., Fang, L., Hipel, K.W. 2002. "A case-based reasoning system for conflict resolution: design and implementation," Engineering Applications of Artificial Intelligence, Vol. 15, pp. 369-383.

[6] Tzafestas, S.G. 1989. "System Fault Diagnosis Using the Knowledge-Based Methodology,” Fault Diagnosis in Dynamic Systems Theory and Applications, Prentice Hall, New York pp. 514-543.

[7] Park, C., Clark, D. R., and Kelly, G. E., "An Overview of HVACSIM", A Dynamic Building/HVAC/Control Systems Simulation Program,” Proceedings of the 1st Annual Building Energy Simulation Conference, Seattle, WA, August 21-22 (1985).

[8] Haves, P. and Norford, L.K.. 1997. "A Standard Simulation Testbed for the Evaluation of Control Algorithms and Strategies. ASHRAE 825-RP Final Report," American Society of Heating, Refrigerating, and Air Conditioning Engineers, Inc., 1793 Tullie Circle N.E. Atlanta, Georgia 30329-2305.

[9] Kohonen, R., et al. 1993. IEA Annex 17 Synthesis Report, Development of Emulation Methods.

[10] Wang, S. 1992. "Emulation and Simulation of Building, HVAC Systems for Evaluating the Building Energy Management System, Doctoral Dissertation,” University of Liège, Belgium.

[11] Castro, N.S., Schein, J., Park, C., Galler, M.A., Bushby, S.T., and House, J.M., 2002, "Results from Simulation and Laboratory Testing of Air Handling Unit and Variable Air Volume Box Diagnostic Tools,” NISTIR 6964. National Institute of Standards and Technology. Gaithersburg, MD. 